\title{
Institutional Investment Constraints and Stock Prices
}

\author{
Jie Cao, Bing Han, and Qinghai Wang*
}

\begin{abstract}
We test the hypothesis that investment constraints in delegated portfolio management may distort demand for stocks, leading to price underreaction to news and stock return predictability. We find that institutions tend not to buy more of a stock with good news that they already overweight; they are reluctant to sell a stock with bad news that they already underweight. Stocks with good news overweighted by institutions subsequently significantly outperform stocks with bad news underweighted by institutions. The impact of institutional investment constraints sheds new light on asset pricing anomalies such as stock price momentum and post-earnings announcement drift.
\end{abstract}

\section{Introduction}

One of the most significant changes in the financial market has been the surge of delegated portfolio management. Increasing portions of U.S. equities are managed by institutional investors such as pension funds and mutual funds. Institutional investors are different from individual investors and face a variety of constraints in their investment decisions. These constraints include restrictions on the market capitalization and the style of stocks in the portfolio, position limits on a stock or an industry, and restrictions on the tracking errors, portfolio turnover, and investment strategies allowed. Such constraints arise as a product of

*Cao, jiecao@cuhk.edu.hk, Business School, Chinese University of Hong Kong; Han (corresponding author), bing.han@rotman.utoronto.ca, Rotman School of Management, University of Toronto, and Shanghai Advanced Institute of Finance, Shanghai Jiao Tong University; and Wang, qinghai .wang@ucf.edu, College of Business Administration, University of Central Florida. We thank Stephen Brown (the editor), Aydogan Alti, Michael Brennan, John Griffin, Jean Helwege, David Hirshleifer, Kewei Hou, Jennifer Huang, Hao Jiang (the referee), Jonathan Lewellen, Stefan Nagel, Laura Starks, Rene Stulz, Michael Stutzer, Siew-Hong Teoh, Sheridan Titman, Ralph Walkling, Russ Wermers, Lu Zheng, and seminar participants at the Hong Kong University of Science and Technology, Peking University, Ohio State University, the University of Texas at Austin, the 2007 Financial Management Association Meetings, and the 2005 Western Finance Association Meetings for helpful discussions and comments. All remaining errors are our own. The work described in this paper was partially supported by a grant from the Research Grant Council of the Hong Kong Special Administrative Region, China (Project No. CUHK 458212). 
regulations, contract requirements, and agency considerations in delegated portfolio management (e.g., Almazan, Brown, Carlson, and Chapman (2004)).

This paper studies the implications of institutional investment constraints for stock demand and valuation. Investment constraints may limit institutional investors' ability to transfer their information into portfolio positions. Institutions could even ignore their own information and "go with the flow" (e.g., Maug and Naik (2011)). This dampened response to information may induce price underreaction for stocks that are affected by institutional investment constraints and generate cross-sectional return predictability as the mispricing subsequently gets corrected.

To empirically measure institutional investment constraints and conduct tests of their impact on institutions' trading and stock prices, we focus on two sets of important institutional investment constraints that are common yet have not been well researched in the literature. The first is the diversification requirement. The Investment Company Act of 1940 explicitly requires that mutual funds must meet various investment diversification standards to qualify for "diversified" status and favorable tax treatment. The Employee Retirement Income Security Act of 1974 (ERISA) requires that pension funds "diversify investments ... so as to minimize the risk of large losses, unless under the circumstances it is clearly prudent not to do so." Civil legal penalties can be imposed on fiduciaries in a lawsuit for violation of ERISA's diversification requirements. In such lawsuits, defendants bear the burden of showing that the decision not to diversify was clearly prudent.

Institutional investors often are subject to both explicit and implicit trackingerror constraints in their investment decisions. The explicit tracking-error constraint as specified in investment contracts restricts the maximal possible deviation of a money manager's portfolio from a given benchmark. Violation of such constraints can result in contract termination and lawsuits. ${ }^{2}$ Even without the contractual tracking-error constraint, portfolio managers have increasingly emphasized the risk of underperforming a benchmark index. The risk of being wrong and alone, popularly recognized as the "maverick risk," is viewed as the greatest peril in investment management by many practitioners (Arnott (2003)). The tracking-error restriction is the second type of institutional investment constraint that motivates our study.

The combination of diversification requirements and tracking-error restrictions could lead to institutional investment decisions that are otherwise difficult to explain. Recent studies document that institutions are reluctant to deviate from the market portfolio or the benchmark they are expected to beat (e.g., Lakonishok, Shleifer, and Vishny (1997), Chan, Chen, and Lakonishok (2002), Cohen, Gompers, and Vuolteenaho (2002), Cremers and Petajisto (2009), and Lewellen (2011)). Such "benchmark investing" contradicts predictions of neoclassic models: Institutional investors are usually viewed as being better informed

\footnotetext{
${ }^{1}$ See Section 404 of ERISA. Although ERISA established the guidelines for private pension plan administration and investment practices, the general guidelines are widely adopted by public pension funds, bank trusts, and, to a large extent, mutual funds (see O'Barr and Conley (1992)).

${ }^{2}$ See, for example, Pensions \& Investments (May 12, 2003), which reports that Merrill Lynch Investment Managers was accused of breaching tracking-error limits on its equities mandate and paid 75 million pounds in settlement.
} 
than individual investors. Thus, they should overweight stocks that have positive news and underweight stocks with negative news. However, because of diversification requirements and tracking-error restrictions, money managers tend to hold large, diversified portfolios that closely mimic the market portfolio (or their policy/performance benchmark). Thus, they may not fully take advantage of their information in their investment decisions. For example, Cohen et al. (2002) estimate that institutions capture only about a third of the gains that they could if they bought more of the stocks they rated as winners and sold more of the ones they rated as losers.

This paper provides further evidence that institutional investment constraints affect money managers' demand for stocks and trading behavior. Because of diversification requirements and tracking-error constraints, institutions cannot or will not keep deviating from their benchmarks. We hypothesize that if money managers already overweight a stock, they may not buy more of the stock even if they receive positive information about the stock. If money managers already underweight a stock, they may be reluctant to sell the stock even if they receive negative information about the stock. Such investment behavior may affect the valuation of stocks and generate testable return patterns.

Our basic hypothesis on the asset pricing implication of institutional investment constraints can be illustrated with an example. Suppose institutions receive a positive signal about a stock, but they already overweight this stock. When investment constraints become binding (e.g., the signal or the overweight is large enough), then institutions' demand schedule for the stock will not shift up by as much as it would without the investment constraints. In other words, their demand for the stock at a given price would be lower than the benchmark case without the investment constraints. When the demand curve for stock is downward sloping, stock with good news that is already overweighted by the institutions would have a lower market-clearing price than the case without the investment constraints. In this sense, the stock is undervalued because the good news is not fully reflected in the market price, thus setting the scene for higher future returns. Similarly, institutions may be constrained from selling stocks that they already underweight even when they have negative information about the stocks. Thus, stocks with bad news that are underweighted by the institutions are overvalued (because the bad news is not fully reflected in the market price) and would have abnormally low future returns.

The impact of investment constraints on stock prices generates crosssectional differences in stock returns that depend on both the direction of institutional investment constraints and the signs of informational signals. For example, when institutions receive good news about a stock, institutions' buying constraints are more likely to be binding if they already overweight the stock than if they underweight it. Thus, among stocks that have good news, those stocks currently overweighted by institutions would experience more price underreactions and deliver higher future returns than those stocks currently underweighted by institutions. Similarly, institutions would have more constraints in selling a stock with bad news if they already underweight it. Thus, among stocks that are experiencing bad news, those stocks currently underweighted by institutions tend to subsequently underperform those currently overweighted by institutions. Finally, for 
stocks without significant news, institutional investment constraints should have little impact on stock prices. Thus, no significant differences are expected in the future returns of stocks that institutions currently overweight and those they underweight when the stocks do not have significant news.

Using quarterly data on institutional equity holdings between 1980 and 2013, we construct two measures of institutional investment constraints for each stock and in each quarter. We compute the fraction of institutions that overweight the stock and the abnormal level of aggregate institutional ownership of the stock. The overweight and underweight measures capture the essence of diversification requirements and tracking-error restrictions. We use two proxies for news, one based on stock returns over a relatively short horizon (e.g., 6 months) and the other based on the firm's quarterly earnings surprises.

We find direct evidence that investment constraints affect institutional trading behavior. Institutions are reluctant to buy stocks they already overweight or sell stocks they already underweight. More importantly, empirical tests strongly support our hypotheses on the asset pricing impact of institutional investment constraints. Among stocks that have good news, those that institutions already overweight subsequently significantly outperform those that institutions underweight. Similarly, for stocks that have bad news, those that institutions underweight subsequently underperform those that institutions overweight. Our results are consistent across all combinations of constraint measures and information proxies.

Our tests reveal interesting interactions between institutional investment constraints and well-known asset pricing anomalies such as stock price momentum and post-earnings announcement drift. For example, we find that a refined momentum strategy that buys only the winner stocks that the institutions overweight and shorts the loser stocks that the institutions underweight is significantly more profitable than the simple momentum strategy that buys all past winners and shorts all past losers. We also find stronger post-earnings announcement drifts for stocks experiencing greater institutional investment constraints.

To the extent that momentum and post-earnings announcement drifts manifest mispricing caused by behavioral-biased investors and institutional investors are the "smart money," our findings are also consistent with the idea that institutional investors' investment constraints limit their ability to arbitrage stock mispricing. ${ }^{3}$ Our main argument is that when institutional investors already significantly overweight or underweight a stock, their investment constraints prevent them from fully utilizing their information advantage. Such information advantage could be about firm fundamentals or stock valuations.

Several recent studies rely on the details of mutual fund holdings to predict stock returns and interpret the findings as evidence of mutual fund managers' information advantage (e.g., Cohen, Polk, and Silli (2010), Wermers, Yao, and Zhao (2012), and Jiang, Verbeek, and Wang (2014)). These studies show that certain variables constructed from mutual fund holdings can predict stock returns in unconditional tests, whereas our hypotheses are conditional on information proxies. Our paper complements and extends these studies. Our results are consistent

\footnotetext{
${ }^{3}$ Lewellen (2011) provides evidence that institutions' investment decisions are constrained by the limits of arbitrage considerations.
} 
with their conclusion that money managers can possess private information. We take it one step further by showing how money managers' investment constraints can limit their ability to trade on their information and studying the associated pricing implications. Our paper uncovers interesting new findings. For example, these studies could not explain our finding that momentum and post-earnings announcement drift are stronger for stocks experiencing greater institutional investment constraints.

Our paper also sheds new light on whether institutions' trading predicts stock returns. At a quarterly frequency, we show that in general, stocks recently bought by the institutions do not subsequently outperform stocks sold by the institutions. However, stocks that institutions recently bought and that reached an overweight position do subsequently significantly outperform stocks that institutions recently sold and that reached an underweight position. Our results help reconcile the general belief that institutions are more informed and the lack of return predictive power of institutional trades on average.

Our results are related to but different from the implications of short-sale constraints. Rather than short-sale constraints, we study institutional investors' buying constraints and selling constraints. We provide the first empirical test on the asset pricing implications of buy-side constraints. In addition, the selling constraints motivated by diversification and tracking-error concerns could be binding even when investors own shares in the stock. In contrast, investors' short-sale constraints apply only to stocks they do not own.

\section{Data and Methodology}

\section{A. Data}

This study uses common stocks listed on the New York Stock Exchange (NYSE), the American Stock Exchange (AMEX), or the National Association of Securities Dealers Automated Quotations (NASDAQ) that appear in the Center for Research in Security Prices (CRSP) and Compustat databases. We exclude stocks that do not have a CRSP share code of 10 or 11, such as real estate investment trusts (REITs), closed-end funds, and American depositary receipts (ADRs). We also exclude stocks priced below $\$ 5$ and stocks in the lowest market-capitalization decile based on NYSE breakpoints as of the end of the previous calendar year. We obtain firm financial information from Compustat. Because of the availability of institutional equity holding data, our sample period is from the first quarter of 1980 through the fourth quarter of 2013.

Institutional equity holding and trading data are obtained from the Thomson Reuters Institutional Holdings (13F) Database. Under the 1978 amendment to the Securities Exchange Act of 1934, all institutional investors managing a portfolio with an investment value of $\$ 100$ million or more are required to file quarterly $13 \mathrm{~F}$ reports with the U.S. Securities and Exchange Commission (SEC) that list their equity positions greater than 10,000 shares or $\$ 200,000$ in market value as of the last date of each quarter. The reporting requirements encompass various types of institutional managers, such as banks, investment companies, pension funds, insurance companies, and brokerage houses. Throughout the paper, the 
terms institutional investors and institutions are used synonymously to refer to $13 \mathrm{~F}$ institutions or managers.

We use institutional equity holdings data to construct measures of institutional investment constraints. Before we do that, we check the data for inconsistent records using reported holding and trading and correct those inconsistencies. For example, stock splits can cause inaccuracies in the data in two ways. First, institutions may fail to report split-adjusted holding and trading records correctly. Second, for the late filings, the holding records for the record date may be erroneously adjusted. In both cases, we use CRSP-reported stock splits to check and adjust the holding data. For the cases where the aggregate institutional ownership of a stock is above $100 \%$, we check the records of all institutions that own the stock for potential errors. For those questionable records we cannot correct, we use the most recent quarter's holding for which no errors are found.

\section{B. Identifying Constrained Stocks}

Our basic hypothesis is that institutional investment constraints distort institutions' demand for stocks and delay the incorporation of their information into stock prices. In order to identify the impact of investment constraints, we use the stock holdings of institutions to measure whether institutions overweight or underweight the stocks in their portfolios. In the following discussion, we explain two methods we use to identify whether a stock is overweighted (underweighted) by institutional investors. The overweight measures are related to the diversification requirements discussed earlier and capture well both the explicit and implicit tracking-error constraints relative to the benchmarks.

Our first measure of investment constraint, called the overweight ratio, is based on an individual institution's equity holdings. At the end of each quarter and for each institution, we first classify whether the institution overweights or underweights a stock in its portfolio. Then, for each stock, the overweight ratio equals the number of institutions that overweight the stock divided by the total number of institutions that hold the stock. By definition, most institutions holding a stock with a high (low) overweight ratio overweight (underweight) it. Thus, a high (low) overweight ratio indicates that institutional investors on average face buying (selling) constraints for the stock.

An empirical difficulty in determining whether an institution overweights a stock is that its benchmark is unobservable to us. To overcome this difficulty, we take advantage of the observed portfolio composition of institutional investors. The composition of an institution's portfolio contains information about its benchmark. Given the diversification requirements and the tracking error concerns, an institution's portfolio should be close to its benchmark. Thus, it makes sense to compare the weights of stocks in an institution's portfolio with those in the valueweighted portfolio of the same stocks. Suppose the institution's portfolio consists of $N_{i}$ shares of stock $i, i=1, \ldots, K$. Stock $i$ 's price per share is $P_{i}$, and market capitalization is $M_{i}$. We say that the institution overweights a stock $i$ if its weight in the portfolio is higher than the corresponding weight in the value-weighted portfolio consisting of the same $K$ stocks: 


$$
\frac{P_{i} \times N_{i}}{\sum_{j=1}^{K} P_{j} \times N_{j}}>\frac{M_{i}}{\sum_{j=1}^{K} M_{j}} .
$$

Intuitively, this means that for any two stocks A and B in the institution's portfolio, the institution holds relatively too much of A (overweights stock A relative to stock B) if the ratio of stock A's weight to stock B's weight in the portfolio is higher than the ratio of their market cap.

One main advantage of our approach for measuring investment constraints is that because we focus on the holdings of the institutions, we can identify a substantial portion of the investment universe of the institutions and consequently identify the investor base of a stock and the potential constraints these investors face. Recent studies provide empirical support for identifying the likely investment targets of the institutional investors based on their holdings. In their studies of the investment decisions of mutual funds, Alexander, Cici, and Gibson (2007) and Coval and Stafford (2007) both show that institutions are far more likely to continue to add to positions in the existing stocks in their portfolios than to initiate positions in new stocks. Based on such evidence, Edmans, Goldstein, and Jiang (2012) and Khan, Kogan, and Serafeim (2012) measure investor demand pressure at the stock level based on mutual fund holdings. In both papers, the authors hypothesize that if a mutual fund holds a stock, and if the mutual fund experiences large inflow (outflow), then the stock in the mutual fund's portfolio experiences positive (negative) demand pressure. For our approach, we further classify, within an institution's portfolio, whether a stock is over- or underweighted by the institution. An overweight ratio, defined as the number of institutions that overweight the stock divided by the total number of institutions that own the stock, captures the likelihood that the institutional investors of the stock face investment constraints when deciding whether to change the weight of the stocks in their portfolios. ${ }^{4}$

Table 1 studies the cross-sectional determinants of the previously defined overweight ratio. The cross-sectional regressions are run for each quarter. The regressors include firm characteristics that are related to institutional investors' preference and are measured at the end of the previous quarter. ${ }^{5}$ We find that firm characteristics such as size, book-to-market ratio, momentum, and Standard \& Poor's (S\&P) 500 index membership are significantly related to a stock's overweight ratio. Specifically, large stocks and stocks that belong to the S\&P 500 index tend to have low overweight ratios, whereas value stocks and past winner stocks tend to have high overweight ratios. In unreported results, we find that institutional ownership for large stocks and S\&P 500 index stocks is more dispersed: A large number of institutions hold these stocks, but many of them hold only a small amount of these stocks, resulting in low overweight ratios. In contrast, the institutional ownership of a typical growth stock or past winner stock tends to be

\footnotetext{
${ }^{4}$ In unreported work, we include institutions that used to own the stock during the last year as well as those that currently own it in the denominator of the overweight ratio. The results are similar to those reported later in the paper.

${ }^{5}$ See, for example, Badrinath, Gay, and Kale (1989), Lakonishok, Shleifer, and Vishny (1992), Del Guercio (1996), Falkenstein (1996), Gompers and Metrick (2001), and Bennett, Sias, and Starks (2003).
} 
TABLE 1

Determinants of Overweight Ratio

Table 1 reports the results of regressions that study the determinants of a stock's overweight ratio, defined as the number
of institutions that overweight a stock divided by the number of institutions that hold the stock. For each quarter between
1980 and 2013 , we run cross-sectional regressions of the overweight ratios of stocks on a set of firm characteristics,
including the natural logarithm of the market capitalization of the stock at the end of the previous quarter (SIZE), a
dummy that takes a value of 1 for stocks that belong to the S\&P 500 index (SP), book-to-market equity ratio as of the end
of the previous year (BM), and the stock return over the previous 12 months (MOM). We report the time-series averages
of the estimated coefficients from the cross-sectional regressions and their $t$-statistics. The sample includes domestic
common stocks traded on NYSE, AMEX, and NASDAQ from 1980 to 2013, excluding REITs, closed-end funds, ADRs,
and stocks that are priced below $\$ 5$ or that rank in the lowest market-capitalization decile as of the end of the previous
calendar year.

more concentrated: A small number of institutions hold the stock, and most of them overweight it. This translates into a higher overweight ratio for the growth stocks and past winner stocks.

Because size, book-to-market ratio, and momentum are significantly related to both the overweight ratio and stock expected returns, these variables may confound the inference in our tests of the asset pricing impact of institutional investment constraints. Therefore, we control for the influence of size, book-to-market ratio, and momentum on the overweight ratio. Throughout the rest of the paper, overweight ratio refers to the residual of the overweight-ratio regression as in model 3 of Table 1. Our results do not change if we use, as the constraint measure, the raw overweight ratio ranked conditionally on stock size alone, or the residuals obtained from other models in Table 1, or the residuals from regressing the raw overweight ratio on size, book-to-market ratio, momentum, an S\&P 500 membership dummy, trading volume, growth option, firm age, volatility, analyst coverage, and analyst dispersion. Note that in all of these variations, the overweight-ratio measure is by construction uncorrelated with size. Thus, there is no size bias in the overweight classification. This point will be empirically verified in Table 3.

Our second measure for whether institutional investors overweight a stock starts with the level of aggregate institutional ownership (IO) of the stock, defined as the number of shares held by all institutions divided by the total common shares outstanding. If the aggregate institutional portfolio replicates the value-weighted market portfolio, then the IO of all stocks should be the same. Relative to the value-weighted market index, institutional investors as a group overweight highIO stocks and underweight low-IO stocks. However, it is not appropriate to make cross-sectional comparisons of investment constraints directly based on raw institutional ownership because institutional investors display distinct preferences for various stock characteristics.

Our second constraint measure is the abnormal institutional ownership for each stock after adjusting for institutional equity preference. At the end of each 
quarter, we run a cross-sectional regression for institutional ownership on size, book-to-market ratio, momentum, and an S\&P 500 membership dummy. ${ }^{6}$ The residual from the IO regression, which we call residual institutional ownership (RES_IO), measures the excess amount of institutional holding for a stock relative to the average institutional ownership for stocks with similar characteristics. Institutions in aggregate overweight stocks with high (positive) RES_IO and underweight stocks with low (negative) RES_IO.

Because the cross-sectional IO regressions are run each quarter, our RES_IO measure takes into account the trend of increasing average institutional ownership as well as the dynamic institutional preference (e.g., Gompers and Metrick (2001), Bennett et al. (2003)). In addition, RES_IO is by construction uncorrelated with such variables as size and book-to-market ratio. This makes it easier to interpret the results of asset pricing tests. In contrast, portfolios sorted directly on stocks' raw institutional ownership level would overlap heavily with a size sort because of the significant positive correlation between size and institutional ownership.

The overweight ratio and RES_IO are complementary measures of institutional investment constraints. The overweight ratio focuses on whether each individual institution overweights a stock in its portfolio and what fraction of institutions holding a stock overweight it. It captures the idea that if a larger proportion of institutions are constrained from buying or selling a stock, the pricing impact of such constraints should be greater. The RES_IO measure complements the overweight ratio measure by taking into consideration the magnitude of the overweight or underweight position at the aggregate level. Empirically, the overweight ratio and RES_IO are positively correlated. The time-series average of the cross-sectional correlation between the two measures is 0.6. Because the two measures are derived differently and may capture different aspects of investment constraints, we employ both measures of constraints in our empirical analysis to ensure the robustness of our results.

\section{Information Proxies}

We propose that investment constraints may prevent institutional investors from fully utilizing the information they possess or reacting properly to public news. Investment constraints are more likely to be binding and affect stock prices for stocks that experience significant news. The impact of investment constraints depends on the combination of investment constraints, that is, whether institutions overweight the stocks (buying constraints) or underweight the stocks (selling constraints), and whether the news is positive or negative.

To identify stocks that are experiencing significant news and, in particular, news that has clearly defined signs, we first use recent stock return as a proxy for news. This approach is consistent with both theoretic models (e.g., Barberis, Shleifer, and Vishny (1998), Hong and Stein (1999)) and many previous empirical studies. At the end of each quarter, we sort stocks into quintiles based on their returns over the last 6 months. Stocks that fall into the top winner quintile generally have significant good news, whereas stocks that fall into the bottom loser quintile

\footnotetext{
${ }^{6}$ In each quarterly cross-sectional regression, the regressors (e.g., firm size) are measured at the end of the previous quarter. Using the residual of several alternative cross-sectional IO regressions as our second constraint measure provides similar results.
} 
generally have significant bad news. With this news proxy, institutional investment constraints have an interesting implication for the profitability of momentum strategy: Momentum profits should be stronger among winners that institutions overweight and among losers that institutions underweight. The idea is that prices of winner stocks that institutions already overweight only partially reflect the positive information that institutions have because their investment constraints limit their demand, which causes stock price underreaction and leads to subsequent high stock return.

We also examine the impact of institutional investment constraints around a concrete and significant news event, the firm's earnings announcement. Baker, Litov, Wachter, and Wurgler (2010) present evidence that institutional investors are better informed about future earnings. Because binding investment constraints could prevent institutional investors from fully exploiting their information, investment constraints can lead to underreaction to their private signals about earnings. Furthermore, even when institutional investors do not possess earnings information ahead of the time, investment constraints could still affect price responses to the public announcement of the earnings. For example, upon the release of surprisingly high earnings, the share price jumps to the point where the stock's weights in the portfolios of those institutions that overweight the stock become excessively high so that instead of holding or buying more of the stock, they have to sell some shares to satisfy the diversification requirements or tracking-error constraints. $^{7}$ In this case, the price reaction to significant earnings news exacerbates investment constraints and leads to trading by constrained institutions in the opposite direction of earnings news. Such trading behavior prevents institutional investors from exploiting the anomalous post-earnings announcement drift and, in fact, could directly contribute to the drift.

For the empirical analysis, our proxy for news is the firm's earnings surprise SUE, measured as the non-split-adjusted earnings per share from the Institutional Brokers' Estimate System (IBES) minus the most recent median analyst forecast preceding the announcement date, standardized by the book value of equity per share. ${ }^{8}$ Based on our hypotheses, institutional investment constraints affect the price drift after earnings announcements: The post-earnings announcement drift should be stronger for stocks with a positive earnings surprise that institutions already overweight and for stocks with a negative earnings surprise that institutions already underweight.

\section{Investment Constraints and Demand for Stocks}

This section examines the impact of investment constraints on institutions' stock demand. Our hypothesis is that institutions are less likely to buy more of the stocks that they already overweight or to sell stocks that they already underweight.

\footnotetext{
${ }^{7}$ We thank the referee for pointing out this important channel through which investment constraints affect institutional investment decisions. Consistent with this idea, our empirical analysis of institutional trading activities around earnings announcements confirms that constrained institutions in aggregate indeed trade in the opposite direction of earnings surprise after earnings announcements.

${ }^{8}$ Alternatively, we measure SUE as the most recent standardized unexpected earnings based on a rolling seasonal random-walk model. The results are similar.
} 
We use both the overweight ratio and RES_IO to study the relation between investment constraints and the trading activity of institutional investors. Such an analysis not only serves as a direct test of our hypothesis but also provides an assessment of the effectiveness of our constraint measures.

Table 2 presents the test results. For each quarter, we first sort stocks into three investment-constraint portfolios based on either overweight ratio (Panel A) or RES_IO (Panel B). Then we calculate the change in the level of institutional ownership, change in the overweight ratio, and change in RES_IO for stocks in each of the three portfolios over the 6 months after as well as the 6 months prior to the portfolio formation. Panel A reports the time-series average of the changes for portfolios sorted on the overweight ratio. Panel B does the same with RES_IO as the sorting variable.

The institutional trading activities documented in Table 2 are consistent with our hypothesis that institutions face buying (selling) constraints on their highoverweight (high-underweight) positions. In Panel A, we find that over the next 6 months, institutions buy more of the stocks that they currently underweight, resulting in a $1.48 \%$ increase in these stocks' institutional ownership. On the other hand, the institutional ownership of stocks currently overweighted by the institutions is reduced on average by $0.01 \%$ over the next 6 months. Further, we find that stocks' (residual) overweight ratios tend to mean-revert toward 0. For example, for stocks currently overweighted by institutions, the change in the overweight ratio is positive over the more recent 6 months but negative over the next 6 months; for stocks currently underweighted by institutions, the change in the overweight ratio is negative over the more recent 6 months but positive over the next 6 months. These results support the hypothesis that institutions cannot or will not keep deviating significantly from their benchmarks.

\section{TABLE 2}

Investment Constraints and Institutional Trading

Table 2 reports institutional trading activity for stocks sorted on overweight ratio $(\mathrm{OR})$ and residual institutional ownership (RES_IO). OR for a stock is defined as the percentage of overweighting institutions unexplained by the cross-sectional regression reported in model 3 of Table 1. RES_IO for a stock is defined as the level of institutional ownership (IO) unexplained by the cross-sectional 10 regression that uses the same regressors as model 3 of Table 1. At the end of each quarter, we sort the stocks into 3 groups (Low, Medium, High) based on OR and RES_IO, respectively. We then calculate the average change in $I O(\Delta I O)$, the average change in OR $(\Delta O R)$, and the average change in RES_IO $\left(\Delta R E S \_I O\right)$ during the 2 quarters prior to and the 2 quarters following the measurement of investment constraints. Panel $A$ reports the time-series mean of the changes for the 3 portfolios sorted based on the overweight ratio. Panel B reports the same for the 3 portfolios sorted based on the residual institutional ownership. The row labeled " $D(H, L)$ " reports the differences for the 3 trading measures between the high-OR (RES_IO) stocks and the low-OR (RES_IO) stocks.

\begin{tabular}{|c|c|c|c|c|c|c|}
\hline & \multicolumn{3}{|c|}{ Previous 6 Months } & \multicolumn{3}{|c|}{ Subsequent 6 Months } \\
\hline & $\Delta \mathrm{IO}$ & $\underline{\Delta O R}$ & $\underline{\Delta R E S \_I O}$ & $\Delta \mathrm{IO}$ & $\Delta \mathrm{OR}$ & $\triangle$ RES_IO \\
\hline \multicolumn{7}{|c|}{ Panel A. Sorted on OR } \\
\hline $\begin{array}{l}\text { Low } \\
\text { Medium } \\
\text { High }\end{array}$ & $\begin{array}{l}0.42 \\
1.35 \\
2.01\end{array}$ & $\begin{array}{r}-2.54 \\
-0.23 \\
2.60\end{array}$ & $\begin{array}{r}-0.62 \\
0.07 \\
0.74\end{array}$ & $\begin{array}{r}1.48 \\
0.80 \\
-0.01\end{array}$ & $\begin{array}{r}2.73 \\
0.11 \\
-3.01\end{array}$ & $\begin{array}{r}0.80 \\
0.11 \\
-0.73\end{array}$ \\
\hline $\begin{array}{l}\mathrm{D}(\mathrm{H}, \mathrm{L}) \\
t \text {-statistic }\end{array}$ & $\begin{array}{l}1.60 \\
9.32\end{array}$ & $\begin{array}{r}5.14 \\
20.04\end{array}$ & $\begin{array}{l}1.36 \\
11.5\end{array}$ & $\begin{array}{r}-1.48 \\
-15.97\end{array}$ & $\begin{array}{r}-5.75 \\
-22.06\end{array}$ & $\begin{array}{r}-1.53 \\
-15.77\end{array}$ \\
\hline \multicolumn{7}{|c|}{$\underline{\text { Panel B. Sorted on RES_IO }}$} \\
\hline $\begin{array}{l}\text { Low } \\
\text { Medium } \\
\text { High }\end{array}$ & $\begin{array}{r}-0.25 \\
0.78 \\
3.25\end{array}$ & $\begin{array}{r}-0.39 \\
-0.06 \\
0.27\end{array}$ & $\begin{array}{r}-1.30 \\
-0.39 \\
1.87\end{array}$ & $\begin{array}{r}2.01 \\
1.36 \\
-1.10\end{array}$ & $\begin{array}{r}0.39 \\
-0.05 \\
-0.51\end{array}$ & $\begin{array}{r}1.42 \\
0.69 \\
-1.93\end{array}$ \\
\hline $\begin{array}{l}\mathrm{D}(\mathrm{H}, \mathrm{L}) \\
t \text {-statistic }\end{array}$ & $\begin{array}{r}3.50 \\
11.28\end{array}$ & $\begin{array}{l}0.66 \\
5.98\end{array}$ & $\begin{array}{r}3.17 \\
22.44\end{array}$ & $\begin{array}{r}-3.12 \\
-24.07\end{array}$ & $\begin{array}{l}-0.89 \\
-8.77\end{array}$ & $\begin{array}{r}-3.35 \\
-25.80\end{array}$ \\
\hline
\end{tabular}


In Panel A of Table 2, the patterns in the changes of the overweight ratio and RES_IO are the same. Further, institutions' trading behavior for portfolios sorted on RES_IO (Panel B) is similar to those sorted on the overweight ratio (Panel A). These results indicate that both the overweight ratio and RES_IO provide similar information as measures of institutional investment constraints.

\section{Investment Constraints and Stock Returns}

Section III presents evidence that investment constraints affect institutions' demand for stocks. This section tests the asset pricing implications of institutional investment constraints. We hypothesize that institutional investment constraints may lead to stock price underreaction to news and stock return predictability. Stocks with good news that are currently overweighted by institutions are undervalued because institutions' buying constraints prevent the good news from being fully reflected in the stock prices. Stocks with bad news that are currently underweighted by institutions are overvalued because of institutions' selling constraints. Among stocks that are experiencing good news, those currently overweighted by institutions experience more institutional buying constraints and tend to subsequently outperform those currently underweighted by institutions. Similarly, among stocks that are experiencing bad news, those currently underweighted by institutions experience more institutional selling constraints and tend to subsequently underperform those currently overweighted by institutions.

To test our hypotheses, we form stock portfolios based on measures of investment constraints and proxies of news. We then compare the average returns of different double-sorted portfolios over several future horizons. We examine whether the return patterns of these double-sorted portfolios are consistent with the hypothesized pricing impact of investment constraints. This is our main approach. Later, we complement this portfolio approach using the Fama-MacBeth (1973) cross-sectional regressions on individual stock returns.

\section{A. Overweight Ratio and Future Stock Returns}

We first present test results using the overweight ratio as the measure of institutional investment constraints and recent 6-month stock return as the proxy for news. Our hypotheses lead to the following predictions: i) Among the past winner stocks, those that have a high overweight ratio (buy-constrained stocks) will subsequently outperform stocks with a low overweight ratio; among the past loser stocks, those that currently have a low overweight ratio (sell-constrained stocks) will subsequently underperform stocks with a high overweight ratio; ii) differences in the overweight ratio are not significantly related to future returns for stocks that are neither recent past winners nor losers (stocks without significant news).

At the end of each quarter, we sort all stocks into 5 quintiles according to their returns over the past 6 months. ${ }^{9}$ We independently sort stocks into three portfolios of high, medium, and low overweight ratios. Fifteen double-sorted

\footnotetext{
${ }^{9}$ We refer to stocks in the top (bottom) quintile sorted based on past 6-month returns as the winner (loser) stocks. The results are robust to skipping a month between portfolio formation and subsequent performance evaluation.
} 
portfolios are obtained by intersecting these two independent sorts. We use 15 double-sorted portfolios to balance two objectives: i) to create enough dispersion in whether stocks are overweighted or underweighted by institutions and whether they are experiencing good news, bad news, or no significant news; and ii) to make sure that each double-sorted portfolio contains enough stocks and is reasonably diversified in order to reduce the standard errors in our test statistics.

Table 3 presents summary characteristics for the momentum and overweight ratios of double-sorted portfolios. The two independent sorts produce fairly balanced portfolios. For example, each portfolio consists of about 135 stocks; the average size-decile ranking is approximately equal across the double-sorted portfolios. In particular, there is no significant difference in size between stocks with a high overweight ratio and those with a low overweight ratio. There is no obvious size bias in the overweight classification. This is expected, because our overweight ratio (as well as RES_IO) already controls for the influence of momentum and other stock characteristics such as size. Stocks in the same overweight ratio tercile have approximately the same level of average institutional ownership and average RES_IO. Stocks with a high overweight ratio also tend to have a high level of institutional ownership and RES_IO.

Panel A of Table 4 reports the average monthly returns for equal-weighted portfolios double sorted on price momentum and the overweight ratio, over the $K$ $(K=3,6)$ months after portfolio formation. Note that our portfolios are formed every 3 months because the institutional equity holding data (and hence our constraint measures) are available quarterly. For the holding period $K>3$ months, at the end of each quarter and for each double-sorted portfolio, there are other portfolios formed at previous quarters that are still "alive." Following Jegadeesh and Titman (1993), we first average the monthly returns of these various aged

\section{TABLE 3}

\section{Characteristics of Momentum-Overweight Ratio Portfolios}

\begin{tabular}{|c|c|c|c|c|c|c|c|c|c|}
\hline \multirow[t]{2}{*}{ Quintile } & $\begin{array}{l}\text { Low- } \\
\text { OR }\end{array}$ & Medium & $\begin{array}{l}\text { High- } \\
\text { OR }\end{array}$ & $\begin{array}{l}\text { Low- } \\
\text { OR }\end{array}$ & Medium & $\begin{array}{l}\text { High- } \\
\text { OR }\end{array}$ & $\begin{array}{l}\text { Low- } \\
\text { OR }\end{array}$ & Medium & $\begin{array}{l}\text { High- } \\
\text { OR }\end{array}$ \\
\hline & \multicolumn{3}{|c|}{$\begin{array}{c}\text { Panel A. } \\
\text { Average Monthly Return }\end{array}$} & \multicolumn{3}{|c|}{$\begin{array}{c}\text { Panel B. } \\
\text { Size Ranking }\end{array}$} & \multicolumn{3}{|c|}{$\begin{array}{l}\text { Panel C. } \\
\text { No. of Obs. }\end{array}$} \\
\hline P1 & -4.03 & -3.83 & -3.73 & 3.96 & 4.45 & 3.88 & 147.1 & 128.2 & 128.3 \\
\hline P2 & -0.41 & -0.42 & -0.41 & 4.90 & 5.48 & 4.70 & 135.1 & 135.9 & 133.2 \\
\hline P3 & 1.31 & 1.31 & 1.34 & 5.24 & 5.82 & 5.02 & 134.8 & 136.6 & 132.8 \\
\hline P4 & 3.18 & 3.15 & 3.19 & 5.41 & 5.90 & 5.08 & 127.2 & 138.4 & 138.6 \\
\hline \multirow[t]{2}{*}{ P5 } & 8.00 & 7.27 & 7.07 & 5.11 & 5.46 & 4.74 & 128.8 & 134.6 & 140.5 \\
\hline & \multicolumn{3}{|c|}{$\begin{array}{c}\text { Panel D. } \\
\text { Overweight Ratio }\end{array}$} & \multicolumn{3}{|c|}{$\begin{array}{c}\text { Panel E. } \\
\text { Institutional Ownership }\end{array}$} & \multicolumn{3}{|c|}{$\begin{array}{c}\text { Panel F. } \\
\text { Residual Institutional Ownership }\end{array}$} \\
\hline P1 & -0.135 & 0.016 & 0.114 & 0.358 & 0.543 & 0.607 & -0.137 & 0.035 & 0.117 \\
\hline P2 & -0.129 & 0.016 & 0.113 & 0.370 & 0.554 & 0.620 & -0.145 & 0.024 & 0.114 \\
\hline P3 & -0.126 & 0.016 & 0.113 & 0.372 & 0.558 & 0.625 & -0.150 & 0.020 & 0.112 \\
\hline P4 & -0.122 & 0.016 & 0.112 & 0.382 & 0.562 & 0.632 & -0.144 & 0.022 & 0.117 \\
\hline P5 & -0.130 & 0.016 & 0.113 & 0.379 & 0.562 & 0.630 & -0.141 & 0.034 & 0.124 \\
\hline
\end{tabular}


TABLE 4

\section{Monthly Returns for Portfolios Based on Price Momentum and Investment Constraints}

Table 4 presents the average monthly returns (in percentages) of portfolios double sorted by momentum and investment constraints for the period 1980-2013. In Panel A, investment constraints are measured by the overweight ratio. In Panel B, investment constraints are measured by RES_IO. At the end of each quarter, all available stocks are sorted into 5 momentum quintiles (P1-P5) based on stock returns over the past 6 months. P1 refers to the portfolio with the lowest return and P5 the highest. The stocks are then independently sorted based on their investment constraints into 3 groups (Low, Medium, High). The momentum-investment constraints portfolios are obtained by intersecting these 2 sorts. We report the average monthly equal-weighted returns of the momentum-investment constraints portfolios over the subsequent 3-6 months (holding period $K=3,6$ months). In addition, we report: i) differences in average monthly returns between the portfolios with high investment constraints and those with low investment constraints for each momentum sort (column labeled " $D(H, L)$ "); ii) the momentum profits within each investment-constraints portfolio (row labeled " $D(5,1)$ )"); and iii) differences in average monthly returns between the high-investment-constraints/P5 portfolio and the low-investment-constraints/P1 portfolio, as well as between the low-investment-constraints/P5 portfolio and the high-investment-constraints/P1 portfolio (row labeled " $\mathrm{P}(\mathrm{H}, \mathrm{L})$ "). We report results based on raw returns in addition to results for portfolio returns that are adjusted for the $5 \times 5$ size and book-to-market characteristics.

\begin{tabular}{|c|c|c|c|c|c|c|c|c|c|c|}
\hline \multirow[b]{2}{*}{ Momentum } & \multicolumn{5}{|c|}{ Raw Return } & \multicolumn{5}{|c|}{ Adjusted Return } \\
\hline & Low & Medium & High & $\mathrm{D}(\mathrm{H}, \mathrm{L})$ & $t$-Stat. & Low & Medium & High & $\mathrm{D}(\mathrm{H}, \mathrm{L})$ & $t$-Stat. \\
\hline \multicolumn{11}{|c|}{ Panel A. Independent Double Sort on Price Momentum and Overweight Ratio } \\
\hline $\begin{array}{l}\text { Panel } A 1 . K= \\
\text { P1 } \\
\text { P2 } \\
\text { P3 } \\
\text { P4 } \\
\text { P5 }\end{array}$ & $\begin{array}{l}3.616 \\
1.225 \\
1.273 \\
1.194 \\
1.273\end{array}$ & $\begin{array}{l}0.947 \\
1.240 \\
1.364 \\
1.298 \\
1.579\end{array}$ & $\begin{array}{l}1.065 \\
1.236 \\
1.342 \\
1.276 \\
1.587\end{array}$ & $\begin{array}{l}0.450 \\
0.012 \\
0.068 \\
0.082 \\
0.315\end{array}$ & $\begin{array}{l}3.71 \\
0.13 \\
0.72 \\
0.89 \\
2.85\end{array}$ & $\begin{array}{r}-0.537 \\
-0.043 \\
-0.040 \\
-0.079 \\
0.032\end{array}$ & $\begin{array}{r}-0.236 \\
-0.011 \\
0.101 \\
0.033 \\
0.338\end{array}$ & $\begin{array}{r}-0.147 \\
-0.031 \\
0.020 \\
-0.023 \\
0.284\end{array}$ & $\begin{array}{l}0.389 \\
0.012 \\
0.060 \\
0.055 \\
0.253\end{array}$ & $\begin{array}{l}3.40 \\
0.14 \\
0.71 \\
0.67 \\
2.50\end{array}$ \\
\hline $\begin{array}{l}\mathrm{D}(5,1) \\
t \text {-statistic }\end{array}$ & $\begin{array}{l}0.657 \\
2.56\end{array}$ & $\begin{array}{l}0.632 \\
2.50\end{array}$ & $\begin{array}{l}0.522 \\
2.30\end{array}$ & & & $\begin{array}{l}0.568 \\
2.51\end{array}$ & $\begin{array}{l}0.574 \\
2.54\end{array}$ & $\begin{array}{l}0.431 \\
2.00\end{array}$ & & \\
\hline $\begin{array}{l}\mathrm{P}(\mathrm{H}, \mathrm{L}) \\
\text { t-statistic }\end{array}$ & $\begin{array}{l}0.208 \\
0.84\end{array}$ & & $\begin{array}{l}0.972 \\
3.87\end{array}$ & & & $\begin{array}{l}0.179 \\
0.790\end{array}$ & & $\begin{array}{l}0.821 \\
3.62\end{array}$ & & \\
\hline $\begin{array}{l}\text { Panel A2. } K= \\
\text { P1 } \\
\text { P2 } \\
\text { P3 } \\
\text { P4 } \\
\text { P5 }\end{array}$ & $\begin{array}{l}0.674 \\
1.156 \\
1.258 \\
1.294 \\
1.291\end{array}$ & $\begin{array}{l}0.975 \\
1.23 \\
1.334 \\
1.342 \\
1.581\end{array}$ & $\begin{array}{l}0.971 \\
1.213 \\
1.373 \\
1.336 \\
1.583\end{array}$ & $\begin{array}{l}0.296 \\
0.057 \\
0.115 \\
0.042 \\
0.292\end{array}$ & $\begin{array}{l}2.70 \\
0.69 \\
1.39 \\
0.52 \\
2.98\end{array}$ & $\begin{array}{r}-0.478 \\
-0.111 \\
-0.035 \\
0.007 \\
0.042\end{array}$ & $\begin{array}{r}-0.213 \\
-0.024 \\
0.061 \\
0.071 \\
0.325\end{array}$ & $\begin{array}{r}-0.239 \\
-0.060 \\
0.070 \\
0.028 \\
0.282\end{array}$ & $\begin{array}{l}0.239 \\
0.051 \\
0.105 \\
0.021 \\
0.241\end{array}$ & $\begin{array}{l}2.36 \\
0.68 \\
1.43 \\
0.30 \\
2.66\end{array}$ \\
\hline $\begin{array}{l}\mathrm{D}(5,1) \\
t \text {-statistic }\end{array}$ & $\begin{array}{l}0.617 \\
2.76\end{array}$ & $\begin{array}{l}0.606 \\
2.70\end{array}$ & $\begin{array}{l}0.613 \\
2.97\end{array}$ & & & $\begin{array}{l}0.520 \\
2.69\end{array}$ & $\begin{array}{l}0.537 \\
2.70\end{array}$ & $\begin{array}{l}0.522 \\
2.71\end{array}$ & & \\
\hline $\begin{array}{l}\mathrm{P}(\mathrm{H}, \mathrm{L}) \\
t \text {-statistic }\end{array}$ & $\begin{array}{l}0.320 \\
1.51\end{array}$ & & $\begin{array}{l}0.909 \\
3.88\end{array}$ & & & $\begin{array}{l}0.281 \\
1.43\end{array}$ & & $\begin{array}{l}0.760 \\
3.72\end{array}$ & & \\
\hline \multicolumn{11}{|c|}{ Panel B. Independent Double Sort on Price Momentum and Residual Institutional Ownership } \\
\hline $\begin{array}{l}\text { Panel B1. } K= \\
\text { P1 } \\
\text { P2 } \\
\text { P3 } \\
\text { P4 } \\
\text { P5 }\end{array}$ & $\begin{array}{l}\beta \\
0.626 \\
1.209 \\
1.350 \\
1.228 \\
1.215\end{array}$ & $\begin{array}{l}0.957 \\
1.332 \\
1.356 \\
1.327 \\
1.591\end{array}$ & $\begin{array}{l}1.049 \\
1.151 \\
1.258 \\
1.231 \\
1.639\end{array}$ & $\begin{array}{r}0.423 \\
-0.057 \\
-0.092 \\
0.002 \\
0.424\end{array}$ & $\begin{array}{r}3.00 \\
-0.50 \\
-0.80 \\
0.02 \\
3.39\end{array}$ & $\begin{array}{r}-0.526 \\
-0.053 \\
0.022 \\
-0.049 \\
-0.031\end{array}$ & $\begin{array}{r}-0.221 \\
0.074 \\
0.090 \\
0.042 \\
0.340\end{array}$ & $\begin{array}{r}-0.178 \\
-0.119 \\
-0.047 \\
-0.040 \\
0.355\end{array}$ & $\begin{array}{r}0.348 \\
-0.066 \\
-0.069 \\
0.009 \\
0.386\end{array}$ & $\begin{array}{r}2.74 \\
-0.63 \\
-0.68 \\
0.09 \\
3.32\end{array}$ \\
\hline $\begin{array}{l}\mathrm{D}(5,1) \\
t \text {-statistic }\end{array}$ & $\begin{array}{l}0.589 \\
2.30\end{array}$ & $\begin{array}{l}0.634 \\
2.55\end{array}$ & $\begin{array}{l}0.590 \\
2.51\end{array}$ & & & $\begin{array}{l}0.495 \\
2.23\end{array}$ & $\begin{array}{l}0.560 \\
2.48\end{array}$ & $\begin{array}{l}0.532 \\
2.40\end{array}$ & & \\
\hline $\begin{array}{l}\mathrm{P}(\mathrm{H}, \mathrm{L}) \\
t \text {-statistic }\end{array}$ & $\begin{array}{l}0.166 \\
0.64\end{array}$ & & $\begin{array}{l}1.013 \\
4.05\end{array}$ & & & $\begin{array}{l}0.147 \\
0.63\end{array}$ & & $\begin{array}{l}0.880 \\
3.90\end{array}$ & & \\
\hline $\begin{array}{l}\text { Panel B2. } K= \\
\text { P1 } \\
\text { P2 } \\
\text { P3 } \\
\text { P4 } \\
\text { P5 }\end{array}$ & $\begin{array}{l}0.637 \\
1.138 \\
1.295 \\
1.308 \\
1.210\end{array}$ & $\begin{array}{l}0.965 \\
1.275 \\
1.377 \\
1.373 \\
1.586\end{array}$ & $\begin{array}{l}1.022 \\
1.188 \\
1.286 \\
1.295 \\
1.655\end{array}$ & $\begin{array}{r}0.385 \\
0.050 \\
-0.009 \\
-0.013 \\
0.445\end{array}$ & $\begin{array}{r}2.96 \\
0.47 \\
-0.09 \\
-0.13 \\
3.88\end{array}$ & $\begin{array}{r}-0.502 \\
-0.126 \\
-0.009 \\
0.022 \\
-0.042\end{array}$ & $\begin{array}{r}-0.222 \\
0.017 \\
0.102 \\
0.077 \\
0.326\end{array}$ & $\begin{array}{r}-0.207 \\
-0.085 \\
-0.006 \\
0.014 \\
0.364\end{array}$ & $\begin{array}{r}0.296 \\
0.041 \\
0.003 \\
-0.008 \\
0.406\end{array}$ & $\begin{array}{r}2.61 \\
0.42 \\
0.03 \\
-0.08 \\
3.85\end{array}$ \\
\hline $\begin{array}{l}\mathrm{D}(5,1) \\
t \text {-statistic }\end{array}$ & $\begin{array}{l}0.572 \\
2.48\end{array}$ & $\begin{array}{l}0.621 \\
2.85\end{array}$ & $\begin{array}{l}0.633 \\
2.99\end{array}$ & & & $\begin{array}{l}0.461 \\
2.34\end{array}$ & $\begin{array}{l}0.548 \\
2.83\end{array}$ & $\begin{array}{l}0.571 \\
2.89\end{array}$ & & \\
\hline $\begin{array}{l}\mathrm{P}(\mathrm{H}, \mathrm{L}) \\
\text {-statistic }\end{array}$ & $\begin{array}{l}0.188 \\
0.82\end{array}$ & & $\begin{array}{l}1.018 \\
4.26\end{array}$ & & & $\begin{array}{l}0.165 \\
0.80\end{array}$ & & $\begin{array}{l}0.866 \\
4.14\end{array}$ & & \\
\hline
\end{tabular}

portfolios in 1 month and then take the time-series average over the sample period to arrive at the average monthly portfolio returns reported in Panel A. In addition to the raw returns, Panel A also reports characteristics-adjusted mean portfolio returns where we first subtract from the raw return of each stock the return of the 
corresponding size and book-to-market matched portfolio and then take the average. The results for holding periods $K=12,24$ months are reported in the Internet Appendix (available at www.jfqa.org) and are qualitatively similar, although the magnitudes of the differences in the average return of stocks with a high versus low overweight ratio decrease as the holding period lengthens. In the following discussions, we focus on the case of $K=6$.

Panel A of Table 4 shows that among past winner and past loser stocks, those with a high overweight ratio tend to have higher subsequent returns. For example, the difference between the average monthly return of winners with a high overweight ratio and winners with a low overweight ratio is $0.29 \%$ and is highly statistically significant. Similarly, losers with a high overweight ratio on average outperform losers with a low overweight ratio by approximately $0.30 \%$ per month during the 6 months after portfolio formation. After controlling for size and bookto-market characteristics for portfolio return, stocks with a high overweight ratio still significantly outperform stocks with a low overweight ratio by approximately $0.24 \%$ per month among both past winner and past loser stocks. Further, this predictive power of the overweight ratio for future stock returns is U-shaped. The differences in the returns between stocks with high and low overweight ratios are not significant among stocks that are neither recent winners nor losers. This holds for both the raw-returns comparisons and the comparisons adjusted for size and book-to-market characteristics.

These results are consistent with the predictions motivated by the pricing impact of institutional investment constraints. They support the idea that institutional investment constraints cause price underreaction to news for stocks affected by the constraints. Note that the forecasting power of the overweight ratio for stock returns does not come from the momentum effect, because we report return differences between stocks within each portfolio sorted by past returns (i.e., we control for the momentum effect).

Panel A of Table 4 further shows an interesting interaction between the effects of investment constraints and momentum: The profitability of the momentum strategy increases monotonically with the degree of investment constraints. The momentum strategy is most profitable among stocks facing high (or binding) investment constraints (i.e., past winner stocks overweighted by institutions and past loser stocks underweighted by institutions). For example, between 1980 and 2013, and for a holding period of $K=6$ months, the momentum strategy applied to these highly constrained stocks generates a significant average return of $0.91 \%$ per month. In contrast, when the momentum strategy is applied to unconstrained stocks (i.e., buy the past winners with a low overweight ratio and sell the past losers with a high overweight ratio), it generates an average monthly return of only $0.32 \%$. This momentum profit is approximately $0.59 \%$ lower than the momentum profits for the constrained stocks. The momentum-strategy profit is $0.61 \%$ per month among the stocks with a medium overweight ratio. ${ }^{10}$ Controlling for size

\footnotetext{
${ }^{10}$ The magnitudes of momentum profits in our paper are lower than those reported by Jegadeesh and Titman (1993) because i) there is a difference in the sample periods (momentum strategy has performed poorly during the last decade in our sample; see, e.g., Daniel and Moskowitz (2013)), and ii) we use 5 return quintiles, which leads to a smaller difference between the past returns of winners
} 
and book-to-market characteristics does not change the patterns of momentum profits across the constraint portfolios.

\section{B. Alternative Measures}

In Section IV.A, we use the overweight ratio as the measure of institutional investment constraints and recent 6-month stock returns to proxy for the news that institutional investors have. This subsection reports additional test results where we use RES_IO as the constraint measure and quarterly earnings surprises as a proxy for news. In addition to providing robustness checks on the results reported in Section IV.A, the analysis offers further insights on the asset pricing implications of institutional investment constraints.

In Panel B of Table 4, we double sort stocks into 15 portfolios based on RES_IO and past 6-month stock returns. The results are similar across various holding periods. The return patterns are identical to those in Panel A. For example, high-RES_IO stocks significantly outperform low-RES_IO stocks in the next 6 months, by approximately $0.45 \%$ per month among the past winner stocks and by approximately $0.39 \%$ per month among the past loser stocks. The predictive power of RES_IO for stock returns is also U-shaped. The differences in the average monthly returns between the high-RES_IO and the low-RES_IO stocks when their past 6-month returns rank in the second to fourth quintiles (i.e., neither winners nor losers) are all smaller than $0.1 \%$ and statistically insignificant. Further, buying high-RES_IO winners (for which institutions face high buying constraints) and selling low-RES_IO losers (for which institutions face high selling constraints) earns a statistically significant $1.02 \%$ return per month over the next 6 months. In contrast, buying low-RES_IO winners and selling high-RES_IO losers returns only approximately $0.19 \%$ per month, which is not significantly different from 0 . Hence, the results here confirm that momentum profits are higher among stocks experiencing more institutional investment constraints.

Next, we study the asset pricing implications of institutional investment constraints using corporate earnings announcements as the information event. At the end of each quarter, we sort stocks into three portfolios based on either the overweight ratio or RES_IO. Then, we independently sort stocks into five portfolios based on their measured earnings surprises from earnings announcements in the next quarter. Finally, we intersect the two sorts to obtain 15 double-sorted portfolios. Following existing studies, we use holding-period returns over a 60trading-day window after earnings announcements and compute the price drift by adjusting for size-decile benchmark portfolio returns over the same period. ${ }^{11}$ The time-series average of the post-earnings announcement price drift for different portfolios is reported in Table 5.

Consistent with the post-earnings announcement drift documented in many previous studies, Table 5 shows that stocks with positive (negative) earnings surprises on the announcement date subsequently have positive (negative) returns.

and losers and thus a smaller momentum profit compared with the strategy that sorts stocks into 10 deciles based on past returns.

${ }^{11} \mathrm{We}$ define the earnings announcement date as date 0 and calculate the 60 -trading-day return from day 2 to day 61 . We obtain similar results when using stock returns adjusted for $5 \times 5$ size and book-to-market characteristics. 
TABLE 5

Excess Returns for Portfolios Based on Earnings Surprise and Constraint Measures

Table 5 reports the average excess returns (in percentages) during the 60 trading days following quarterly earnings announcements for earnings surprise-investment constraints double-sorted portfolios for the period 1980-2013. The excess returns are raw returns adjusted for size-decile portfolio returns. The 2 measures for investment constraints are the overweight ratio and RES_IO. Panel A reports the results using the overweight ratio as the constraint measure, and Panel $B$ reports the results based on RES_IO. Earnings surprise is defined as the actual earnings per share minus consensus analyst forecast, standardized by the per-share book value of equity. Each quarter, all available stocks are sorted into quintiles (E1-E5) based on the next quarter's earnings surprise. E1 refers to the portfolio with the most negative earnings surprise and E5 the most positive. The stocks are then independently sorted based on their overweight ratios or RES_IO into 3 groups: Low, Medium, and High. The earnings surprise-overweight ratio (or earnings surprise-RES_IO) portfolios are obtained by intersecting the 2 sorts. We report average excess returns and the differences in the average excess returns between the portfolios with a high overweight ratio (or RES_IO) and those with a low overweight ratio (or RES_IO) for each earnings-surprise sort (column labeled " $\mathrm{D}(\mathrm{H}, \mathrm{L})$ ").

\begin{tabular}{|c|c|c|c|c|c|}
\hline Earnings Surprise & Low & Medium & High & $\underline{D(H, L)}$ & $t$-Stat. \\
\hline \multicolumn{6}{|c|}{ Panel A. Independent Double Sort on Earnings Surprise and Overweight Ratio } \\
\hline $\begin{array}{l}\text { E1 } \\
\text { E2 } \\
\text { E3 } \\
\text { E4 } \\
\text { E5 }\end{array}$ & $\begin{array}{r}-1.226 \\
-1.079 \\
-0.091 \\
1.068 \\
3.673\end{array}$ & $\begin{array}{r}-0.579 \\
-0.442 \\
0.087 \\
1.661 \\
4.126\end{array}$ & $\begin{array}{r}-0.362 \\
-0.959 \\
-0.001 \\
1.800 \\
4.608\end{array}$ & $\begin{array}{l}0.864 \\
0.109 \\
0.091 \\
0.732 \\
0.936\end{array}$ & $\begin{array}{l}2.62 \\
0.33 \\
0.29 \\
2.14 \\
2.58\end{array}$ \\
\hline \multicolumn{6}{|c|}{ Panel B. Independent Double Sort on Earnings Surprise and RES_IO } \\
\hline $\begin{array}{l}\text { E1 } \\
\text { E2 } \\
\text { E3 } \\
\text { E4 } \\
\text { E5 }\end{array}$ & $\begin{array}{r}-1.312 \\
-1.118 \\
-0.209 \\
1.066 \\
3.612\end{array}$ & $\begin{array}{r}-0.542 \\
-0.620 \\
-0.124 \\
1.542 \\
4.245\end{array}$ & $\begin{array}{r}-0.431 \\
-0.717 \\
0.229 \\
1.858 \\
4.446\end{array}$ & $\begin{array}{l}0.881 \\
0.392 \\
0.438 \\
0.793 \\
0.834\end{array}$ & $\begin{array}{l}2.22 \\
1.09 \\
1.38 \\
2.08 \\
2.66\end{array}$ \\
\hline
\end{tabular}

More interestingly, we find that stocks with extreme positive earnings surprises have the largest (most positive) post-earnings announcement drift when they are already overweighted by the institutions. When we control for positive earnings surprises, we find that, on average, stocks that institutions overweight outperform stocks that they underweight by a significant $0.94 \%$ over the 60 trading days following the earnings announcement (Panel A). Among the stocks having extreme negative earnings surprises, those that institutions already underweight have lower future returns (i.e., more negative drift) than those that institutions overweight. The difference is $-0.86 \%$ and statistically significant. Results are similar when we use RES_IO as the measure of institutional investment constraints (Panel B). Finally, consistent with our prediction and the results in Table 4, the predictive power of constraint measures for post-earnings announcement drift is U-shaped.

These results corroborate those in Section IV.A and provide further support for the hypothesized impact of institutional investment constraints on stock prices. Our results also suggest that institutional investment constraints play an important role in explaining the post-earnings announcement drift. This is consistent with Hirshleifer, Myers, Myers, and Teoh (2008), who conclude that individual investors do not drive post-earnings announcement drift. Recent research on postearnings announcement drift has generally pointed to investors' underreaction induced by investor behavioral bias as the cause of such price drift. Our results show that investment constraints inherent in investor portfolio decisions could also lead to underreaction to earnings news and the subsequent price drift.

One distinctive feature of our investment constraint measures is that they are constructed to capture both buying and selling constraints. Compared with studies that solely focus on short-sale constraints, our approach allows us to consider constraints on both buying and selling decisions and to consider selling constraints 
that could become binding before holdings reach 0 . Given that most of the institutional investors are long-only investors, our results should be stronger when there is negative news and institutions underweight the stocks than when they overweight stocks that have positive news. The results in Tables 4 and 5 support the idea that our measures are better able to capture the binding constraints for stocks with news. For example, Panel B of Table 4 (holding period $K=3$ months) shows that for stocks experiencing negative news, those that are most underweighted by institutions have an average monthly return of $0.626 \%$, which is significantly lower than the $0.957 \%$ monthly average returns for stocks that are not suffering from institutional investment constraints. By comparison, the stocks experiencing positive news that are overweighted by institutions have an average monthly return of $1.639 \%$, which is not significantly different from the $1.591 \%$ average monthly return for stocks not facing significant institutional investment constraints. In unreported results (available from the authors), we find that the same comparisons hold for Fama-French (1992) 3-factor model alphas as well as for the returns adjusted for size and book-to-market characteristics. In addition, the magnitudes of the Fama-French 3-factor alphas or characteristics-adjusted returns for the constrained stocks experiencing negative news are approximately twice the size of those for the constrained stocks experiencing positive news. These results confirm the asymmetric effects of institutional investment constraints.

\section{Further Robustness Checks and Alternative Explanations}

In this subsection, we first verify the robustness of our main results to variations in the sorting procedures as well as the use of Fama-MacBeth (1973) regressions. We also examine how the effects of the investment constraints vary across different types of institutions. We further evaluate a potential alternative explanation of our results based on informed institutions.

All of the results reported thus far are robust to variations in the double-sort procedure, such as sorting on returns for the past 3 months or 1 year instead of the 6-month return or using 10 past-return-sorted portfolios and 5 constraint-sorted portfolios. Similar results are obtained when we form portfolios each month instead of each quarter using the most recent institutional ownership. Further, our results remain qualitatively the same when we use the previous quarter's institutional holdings data when measuring institutions' investment constraints.

When we repeat our analysis separately for the large stocks and for the small stocks, our results hold in both subsamples. In addition, our results hold up in two subperiods (Jan. 1980-Dec. 1995 and Jan. 1996-Dec. 2013). Our portfoliosorting results also hold for the Fama-French (1992) 3-factor alpha, beyond the raw returns and characteristics-adjusted returns reported previously.

We run Fama-MacBeth (1973) cross-sectional regressions to further check the robustness of the predictive power of our institutional investment constraint measures for stock returns obtained using the portfolio approach. The crosssectional regressions are run each quarter. In quarter $t$ 's regression, the dependent variable is the average monthly return for individual stocks over that quarter. The key regressor is the overweight ratio (or RES_IO) at the end of quarter $t-1$. The control variables include size (log market cap measured at the end of quarter $t-1$ ), momentum (past 6-month stock return), book-to-market equity ratio 
and return on equity (both measured as of the end of the previous year), average monthly turnover ratio over the last 2 quarters, volatility of stock return, and institutional trading (change in institutional ownership) over the last 2 quarters. The stock characteristics we include are standard in cross-sectional return regressions.

Table 6 reports the time-series mean of the coefficient estimates (and their $t$-statistics) for the cross-sectional regressions. Model 1 of Panel A shows that the overweight ratio positively predicts future stock returns above and beyond all the control variables just mentioned. The same result holds in model 1 of Panel $\mathrm{B}$, which uses RES_IO as the constraint measure. In particular, the relation between our institutional investment constraint measures and future stock returns is not driven by institutional trading. In fact, at a quarterly frequency, institutional trading does not significantly predict subsequent stock returns in our sample.

One of our findings that shows up consistently in Tables 4 and 5 is the U-shaped forecasting power of our constraint measure for stock returns: It is significant only for stocks that are experiencing significant news. To check this result

\section{TABLE 6}

\section{Fama-MacBeth Cross-Sectional Regressions}

Table 6 reports the results of Fama-MacBeth (1973) cross-sectional regressions of individual stock returns on firmcharacteristics variables and measures of investment constraints. The cross-sectional regressions are run once each quarter. In quarter t's regression, the dependent variable is the average monthly stock returns over the same quarter. Overweight ratio (OR) and residual institutional ownership (RES_IO) are measured at the end of quarter $t-1$. The control variables include firm market capitalization (SIZE) measured at the end of the last quarter, the book-to-market equity ratio $(\mathrm{BM})$ and return on equity (ROE) measured as of the end of the previous year, the standard deviation of monthly returns over the past 2 years expressed in percentages (VOLATILITY), the average monthly turnover over the past 6 months (TURNOVER), the average monthly stock returns over the past 6 months (MOMENTUM), and the net institutional trading over the past 6 months (TRADING). Panel A reports the results based on the overweight ratio. Model 2 adds as regressors the interaction of $\mathrm{OR}$ with a dummy that takes a value of 1 for stocks with a past-6-month return that is in the lowest quintile (loser stocks) as well as the interaction of OR with a winner dummy. Panel B reports the results based on RES_IO. Model 2 adds as regressors the interaction of RES_IO with a loser dummy (LOSER) and the interaction of RES_IO with a winner dummy (WINNER). The table reports the time-series averages of the estimated coefficients from the cross-sectional regressions and their $t$-statistics. The sample includes domestic common stocks traded on NYSE, AMEX, and NASDAQ from 1980 to 2013, excluding REITs, closed-end funds, ADRs, and stocks that are priced below $\$ 5$ or that rank in the lowest market-capitalization decile as of the end of the previous calendar year.

\begin{tabular}{|c|c|c|c|c|}
\hline \multirow[b]{2}{*}{ Variable } & \multicolumn{2}{|c|}{ Model 1} & \multicolumn{2}{|c|}{ Model 2} \\
\hline & Estimate & $t$-Stat. & Estimate & $t$-Stat. \\
\hline \multicolumn{5}{|l|}{ Panel A. Impact of OR } \\
\hline $\begin{array}{l}\text { Intercept } \\
\text { SIZE } \\
\text { BM } \\
\text { ROE } \\
\text { VOLATILITY } \\
\text { TURNOVER } \\
\text { MOMENTUM } \\
\text { TRADING } \\
\text { OR } \\
\text { LOSER } \times \text { OR } \\
\text { WINNER } \times \text { OR }\end{array}$ & $\begin{array}{r}1.374 \\
-0.012 \\
0.122 \\
0.098 \\
-0.029 \\
-0.021 \\
5.116 \\
-0.129 \\
0.764\end{array}$ & $\begin{array}{r}7.58 \\
-1.47 \\
1.43 \\
0.90 \\
-1.66 \\
-2.89 \\
3.38 \\
-0.54 \\
2.70\end{array}$ & $\begin{array}{r}1.374 \\
-0.012 \\
0.118 \\
0.077 \\
-0.028 \\
-0.021 \\
5.048 \\
-0.168 \\
0.415 \\
1.079 \\
0.958\end{array}$ & $\begin{array}{r}7.49 \\
-1.41 \\
1.38 \\
0.70 \\
-1.62 \\
-2.97 \\
3.34 \\
-0.71 \\
1.43 \\
2.62 \\
2.08\end{array}$ \\
\hline \multicolumn{5}{|c|}{ Panel B. Impact of RES_IO } \\
\hline $\begin{array}{l}\text { Intercept } \\
\text { SIZE } \\
\text { BM } \\
\text { ROE } \\
\text { VOLATILITY } \\
\text { TURNOVER } \\
\text { MOMENTUM } \\
\text { TRADING } \\
\text { RES_IO } \\
\text { LOSER } \times \text { RES_IO } \\
\text { WINNER } \times \text { RES_IO }\end{array}$ & $\begin{array}{r}1.414 \\
-0.009 \\
0.086 \\
0.164 \\
-0.029 \\
-0.021 \\
5.527 \\
-0.261 \\
0.461\end{array}$ & $\begin{array}{r}7.39 \\
-1.17 \\
0.88 \\
1.31 \\
-1.57 \\
-3.00 \\
3.61 \\
-0.95 \\
2.20\end{array}$ & $\begin{array}{r}1.411 \\
-0.009 \\
0.087 \\
0.152 \\
-0.028 \\
-0.022 \\
5.389 \\
-0.310 \\
0.210 \\
0.601 \\
0.807\end{array}$ & $\begin{array}{r}7.32 \\
-1.18 \\
0.88 \\
1.19 \\
-1.53 \\
-3.06 \\
3.54 \\
-1.13 \\
1.00 \\
2.27 \\
3.08\end{array}$ \\
\hline
\end{tabular}


using the Fama-MacBeth (1973) regressions, we introduce two additional regressors in model 2 of Panel A of Table 6, which are the interactions of the overweight ratio with a dummy for the past-6-month winners and with a dummy for the past6-month losers. Consistent with previous results based on the portfolio approach, these two interaction variables are both significantly positively related to future stock returns in the Fama-MacBeth (1973) regressions as well. After controlling for these interaction terms, the overweight ratio variable itself is no longer statistically significant. The same results are obtained in Panel B with RES_IO as the constraint measure. Thus, the U-shaped pattern in the predictive power of our constraint measures for stock returns is confirmed in the cross-sectional regressions.

The magnitudes of the return spreads generated by the constraint measures as implied by the Fama-MacBeth (1973) regressions are close to those based on the portfolio approach reported earlier. For example, the estimated coefficient for the interaction of the overweight ratio with the losers dummy is 1.079 . Given the 0.25 average difference in the overweight ratio between the high and low tercile (see Table 3), this coefficient translates into an expected return difference between the losers with a high overweight ratio and the losers with a low overweight ratio of $0.27 \%$ per month over the next quarter. For comparison, the return difference (adjusted for size and book-to-market characteristics) between the high- and low-overweight-ratio losers (for holding period $K=3$ in Table 4) based on the portfolio sorting approach is $0.39 \%$.

We next examine how the varying investment constraints faced by different types of institutions affect the strength of our results. We follow Bushee and Noe (2000) in classifying institutional investors in the $13 \mathrm{~F}$ database into three different groups: dedicated, quasi-indexers, and transient institutions. Dedicated institutions are those institutions that hold a small number of stocks but over a long time period, and they represent a very small portion $(5 \%)$ of the institutions in the sample. Quasi-indexers include $70 \%$ of the $13 \mathrm{~F}$ institutions, and these institutions follow but also deviate to a certain extent from their benchmarks. The transient institutions (approximately $25 \%$ of the $13 \mathrm{~F}$ institutions) are those that trade actively in the stocks and do not have clearly specified benchmarks.

In Table 7, we report the results separately for two types of institutions, quasiindexers and transient institutions. Based on our hypothesis, the types of institutional investors that are mostly likely to be constrained are the quasi-indexers, institutions that cannot deviate substantially from their benchmarks even when they possess valuable information. The results in Table 7 confirm this prediction. When using the overweight ratio as the constraint measure, we find that the investment constraints faced by the quasi-indexers have a much stronger effect on future stock returns, with a clear U-shape across portfolios sorted by recent stock returns (a proxy for news). In comparison, the results for the transient institutions are much weaker and sometimes insignificant. In an unreported test, we verify that the results remain the same when we use RES_IO as the constraint measure.

Last, we evaluate an alternative explanation of our results that is based on informed institutions. One potential explanation for our finding is that the overweight ratio and RES_IO may simply reflect institutions' information that enables them to shift their portfolios in advance of abnormally high or low returns. Under this explanation, stocks that institutions currently overweight (underweight) are 
TABLE 7

Monthly Returns for Portfolios Based on Price Momentum and the Investment Constraints by Different Types of Institutions

\begin{tabular}{|c|c|c|c|c|c|c|c|c|c|c|}
\hline \multirow[b]{2}{*}{ Momentum } & \multicolumn{5}{|c|}{$K=3$} & \multicolumn{5}{|c|}{$K=6$} \\
\hline & $\underline{\text { Low }}$ & Medium & $\underline{\text { High }}$ & $\underline{\mathrm{D}(\mathrm{H}, \mathrm{L})}$ & t-Stat. & Low & Medium & $\underline{\text { High }}$ & $\underline{\mathrm{D}(\mathrm{H}, \mathrm{L})}$ & t-Stat. \\
\hline \multicolumn{11}{|c|}{ Panel A. Quasi-Indexer } \\
\hline P1 & 0.621 & 0.955 & 1.104 & 0.484 & 3.81 & 0.674 & 0.975 & 1.013 & 0.339 & 2.83 \\
\hline P2 & 1.211 & 1.237 & 1.263 & 0.051 & 0.57 & 1.157 & 1.189 & 1.255 & 0.098 & 1.30 \\
\hline P3 & 1.237 & 1.381 & 1.359 & 0.122 & 1.42 & 1.245 & 1.328 & 1.395 & 0.150 & 2.00 \\
\hline P4 & 1.170 & 1.309 & 1.276 & 0.106 & 1.21 & 1.271 & 1.354 & 1.338 & 0.067 & 0.91 \\
\hline P5 & 1.353 & 1.491 & 1.616 & 0.263 & 2.53 & 1.360 & 1.533 & 1.593 & 0.234 & 2.56 \\
\hline$D(5,1)$ & 0.732 & 0.536 & 0.512 & & & 0.685 & 0.558 & 0.581 & & \\
\hline$t$-statistic & 2.90 & 2.11 & 2.26 & & & 3.02 & 2.49 & 2.89 & & \\
\hline $\mathrm{P}(\mathrm{H}, \mathrm{L})$ & 0.248 & & 0.995 & & & 0.347 & & 0.919 & & \\
\hline$t$-statistic & 1.03 & & 3.96 & & & 1.65 & & 3.91 & & \\
\hline \multicolumn{11}{|c|}{$\underline{\text { Panel B. Transient Institutions }}$} \\
\hline P1 & 0.727 & 0.921 & 0.940 & 0.213 & 1.88 & 0.776 & 0.968 & 0.857 & 0.081 & 0.84 \\
\hline P2 & 1.210 & 1.273 & 1.215 & 0.005 & 0.05 & 1.170 & 1.209 & 1.219 & 0.049 & 0.56 \\
\hline P3 & 1.299 & 1.318 & 1.349 & 0.051 & 0.54 & 1.293 & 1.301 & 1.357 & 0.064 & 0.77 \\
\hline P4 & 1.243 & 1.272 & 1.272 & 0.029 & 0.30 & 1.312 & 1.320 & 1.346 & 0.034 & 0.41 \\
\hline P5 & 1.346 & 1.559 & 1.542 & 0.195 & 1.78 & 1.319 & 1.532 & 1.590 & 0.272 & 2.93 \\
\hline$D(5,1)$ & 0.619 & 0.638 & 0.602 & & & 0.543 & 0.564 & 0.734 & & \\
\hline$t$-statistic & 2.54 & 2.49 & 2.51 & & & 2.54 & 2.50 & 3.35 & & \\
\hline $\mathrm{P}(\mathrm{H}, \mathrm{L})$ & 0.406 & & 0.815 & & & 0.462 & & 0.814 & & \\
\hline$t$-statistic & 1.58 & & 3.50 & & & 2.06 & & 3.75 & & \\
\hline
\end{tabular}

just those that they recently bought (sold) based on positive (negative) private information. When the information later becomes public, the stocks they have bought (and now overweight) would have high future returns, and the stocks they have sold (and now underweight) would have low future returns.

We conduct formal tests of the informed-trading hypothesis to differentiate the informed-institution story and the investment-constraint hypothesis. The tests provide further insight into the underlying causes of the return predictability of our constraint measures. In Panel A of Table 8, we report post formation returns for portfolios double sorted on price momentum and net institutional trading (change in institutional ownership) over the past 6 months. The table format is the same as that of Table 4, except we now sort on institutional trading rather than stocks' overweight ratio. In contrast to the predictive power of our constraint measures, we do not find any evidence that recent institutional trading positively predicts stock returns over the next 3 or 6 months. ${ }^{12}$ This finding is also consistent with the cross-sectional regression results in Table 6 , which show insignificant coefficient estimates for the institutional trading variable.

Panel B of Table 8 helps us better understand how institutional trading and investment constraints interact to affect stock prices and returns. For this table, we double sort stocks into 9 portfolios based on the change in institutional ownership over the past 6 months and the current overweight ratio, and then report the

\footnotetext{
${ }^{12}$ Gompers and Metrick (2001) and Cai and Zheng (2004), employing the same data we use, also find no evidence that institutional trading predicts future returns at a quarterly frequency.
} 
TABLE 8

Monthly Returns for Portfolios Based on Institutional Trading and Investment Constraints

Panel A of Table 8 presents average monthly returns (in percentages) of portfolios double sorted on stock price momentum and institutional trading activity. Panel B presents average monthly returns (in percentages) of portfolios double sorted on institutional trading activity and the overweight ratio. In Panel A, at the end of each quarter, all available stocks are sorted into 5 momentum quintiles (P1-P5) based on stock returns over the past 6 months. P1 refers to the portfolio with the lowest return and P5 the highest. The stocks are then independently sorted based on aggregate institutional trading activity during the same 6-month period into 3 groups (Sell, Medium, Buy). The momentum-trading portfolios are obtained by intersecting these 2 sorts. We report average monthly equal-weighted returns of the momentum-trading portfolios over the subsequent 3 to 6 months (holding period $K=3,6$ months). We also report the differences in the average monthly returns between the portfolios with high net institutional trading and those with low net institutional trading for each momentum sort (column labeled " $\mathrm{D}(\mathrm{B}, \mathrm{S})$ "). In Panel $\mathrm{B}$, we double sort stocks based on aggregate institutional trading activity during the past 6 months (Sell, Medium, Buy) and the overweight ratio of the stocks at the end of the quarter (Low-OR, Medium, High-OR). We report average monthly equal-weighted returns of the trading-OR portfolios over the subsequent 3 to 6 months (holding period $K=3,6$ months). In addition, we report: i) the differences in the average monthly returns between the portfolios with a high overweight ratio and those with a low overweight ratio for each institutional trading sort (column labeled " $\mathrm{D}(\mathrm{H}, \mathrm{L})$ "); ii) the differences in the institutional trading portfolio within each overweight-ratio portfolio (row labeled " $\mathrm{D}(\mathrm{B}, \mathrm{S})$ "); and iii) the difference in the average monthly returns between the highoverweight-ratio/Buy portfolio and the low-overweight-ratio/Sell portfolio, as well as between the low-overweight-ratio/Buy portfolio and the high-overweight-ratio/Sell portfolio (row labeled " $\mathrm{P}(\mathrm{H}, \mathrm{L})$ ").

Panel A. Independent Double Sort on Price Momentum and Institutional Trading Activity

\begin{tabular}{|c|c|c|c|c|c|c|c|c|c|c|}
\hline \multirow[b]{2}{*}{ Momentum } & \multicolumn{5}{|c|}{$K=3$} & \multicolumn{5}{|c|}{$K=6$} \\
\hline & Sell & Medium & Buy & $\mathrm{D}(\mathrm{B}, \mathrm{S})$ & $t$-Stat. & Sell & Medium & Buy & $\mathrm{D}(\mathrm{B}, \mathrm{S})$ & $t$-Stat. \\
\hline P1 & 0.742 & 0.769 & 0.566 & -0.176 & -1.87 & 0.752 & 0.828 & 0.617 & -0.135 & -1.79 \\
\hline P2 & 1.203 & 1.270 & 1.137 & -0.066 & -0.80 & 1.186 & 1.196 & 1.089 & -0.096 & -1.47 \\
\hline P3 & 1.297 & 1.385 & 1.139 & -0.158 & -2.10 & 1.309 & 1.335 & 1.197 & -0.113 & -1.82 \\
\hline P4 & 1.248 & 1.207 & 1.260 & 0.012 & 0.17 & 1.318 & 1.312 & 1.295 & -0.023 & -0.41 \\
\hline P5 & 1.495 & 1.411 & 1.479 & -0.016 & -0.17 & 1.502 & 1.447 & 1.472 & -0.029 & -0.37 \\
\hline
\end{tabular}

Panel B. Independent Double Sort on Institutional Trading Activity and Overweight Ratio

\begin{tabular}{|c|c|c|c|c|c|c|c|c|c|c|}
\hline \multirow[b]{2}{*}{ Trade } & \multicolumn{5}{|c|}{$K=3$} & \multicolumn{5}{|c|}{$K=6$} \\
\hline & Low-OR & Medium & High-OR & $\underline{\mathrm{D}(\mathrm{H}, \mathrm{L})}$ & $t$-Stat. & Low-OR & Medium & High-OR & $\underline{\mathrm{D}(\mathrm{H}, \mathrm{L})}$ & $t$-Stat. \\
\hline Sell & 1.030 & 1.300 & 1.312 & 0.282 & 3.30 & 1.094 & 1.312 & 1.276 & 0.182 & 2.28 \\
\hline Medium & 1.121 & 1.300 & 1.338 & 0.217 & 2.55 & 1.158 & 1.313 & 1.342 & 0.184 & 2.33 \\
\hline Buy & 1.129 & 1.258 & 1.290 & 0.161 & 1.82 & 1.106 & 1.271 & 1.304 & 0.197 & 2.47 \\
\hline $\mathrm{D}(\mathrm{B}, \mathrm{S})$ & 0.099 & -0.042 & -0.023 & & & 0.012 & -0.041 & 0.028 & & \\
\hline$t$-statistic & 1.180 & -0.500 & -0.290 & & & 0.170 & -0.600 & 0.430 & & \\
\hline $\begin{array}{l}\mathrm{P}(\mathrm{H}, \mathrm{L}) \\
\text { t-statistic }\end{array}$ & -0.183 & & 0.260 & & & -0.170 & & 0.209 & & \\
\hline
\end{tabular}

postformation average monthly portfolio returns for holding periods of 3 and 6 months. We find that after controlling for changes in institutional ownership, stocks with a high overweight ratio still significantly outperform stocks with a low overweight ratio.

Interestingly, we find that whether institutions' trades predict future stock returns depends on whether they experience investment constraints on these stocks. Stocks that institutions recently bought but still underweight do not have high future returns, and stocks that institutions recently sold yet still overweight do not have low future returns. Conversely, stocks that institutions recently bought and now overweight significantly outperform stocks that institutions recently sold and currently underweight. The difference is approximately $0.28 \%$ per month and economically significant. As institutions trade and reach binding investment constraints, they cannot fully take advantage of their information. Their information becomes reflected in the stock price only after a delay. This delay gives rise to return predictability and profitable opportunity to follow the trades of informed (but constrained) institutions, even with a lag such as 1 quarter. 


\section{Conclusions}

Institutional investors face constraints because of their restrictive investment policies, which are not binding on individuals. These additional restrictions are a mitigation of the legal liability imposed on institutional fiduciaries by laws and regulations such as ERISA and the Prudent Investor Rule.

This study examines the impact of institutional investment constraints on the aggregate demand for stocks and the cross section of stock returns. Using institutional equity holding data between 1980 and 2013, we find that institutional investors are less likely to buy more of the stocks that they already overweight even when there is good news about the stocks. They are also reluctant to sell the stocks that they already underweight even when they have bad news about the stocks. This behavior is consistent with institutional investment constraints such as diversification requirements and tracking-error restrictions.

We test hypotheses about the impact of institutional investment constraints on stock prices: Stocks that institutions overweight may underreact to good news and become undervalued; stocks that institutions underweight may underreact to bad news and become overvalued. Consistent with the hypotheses, we find that among stocks that have good news, those that institutions overweight significantly subsequently outperform those that institutions underweight. Similarly, for stocks that have bad news, those that institutions underweight subsequently underperform those that institutions overweight. Further, we find that the momentum strategy and post-earnings announcement drift are both stronger among stocks that experience high institutional investment constraints.

Our results support the argument of Allen (2001) that financial institutions matter for asset pricing. They indicate that asset pricing anomalies may be importantly related to institutional investment constraints. In a similar vein, Alankar, Blaustein, and Scholes (2014) demonstrate that investment managers may not eliminate the observed asset pricing anomalies because they may contribute to their existence. DeVault, Sias, and Starks (2014) argue that institutional investors are the sentiment traders whose demand shocks drive prices from fundamental value. Edelen, Ince, and Kadlec (2014) document that institutions are on the wrong side of anomalies more often than not. Goldman and Slezak (2003) show that delegated portfolio management may distort managers' incentive to trade on long-term information and cause stock mispricing. It seems a fruitful venue for future research to explore further how issues arising from delegated portfolio management affect money managers' portfolio decisions and stock prices in equilibrium, following the lead of Roll (1992), Carpenter (2000), Cornell and Roll (2005), Cuoco and Kaniel (2011), and others.

\section{References}

Alankar, A.; P. Blaustein; and M. Scholes. "The Cost of Constraints: Risk Management, Agency Theory and Asset Prices.” Working Paper, Stanford University (2014).

Alexander, G.; G. Cici; and S. Gibson. "Does Trade Motivation Matter? An Analysis of Mutual Fund Trades.” Review of Financial Studies, 20 (2007), 125-150.

Allen, F. “Do Financial Institutions Matter?” Journal of Finance, 56 (2001), 1165-1175.

Almazan, A.; K. C. Brown; M. Carlson; and D. A. Chapman. "Why Constrain Your Mutual Fund Manager?" Journal of Financial Economics, 73 (2004), 289-321. 
Arnott, R. "What Risk Matters? A Call for Papers!" Financial Analysts Journal, 59 (2003), 6-8.

Badrinath, S. G.; G. D. Gay; and J. R. Kale. "Patterns of Institutional Investment, Prudence, and the Managerial 'Safety-Net' Hypothesis.” Journal of Risk and Insurance, 56 (1989), 605-629.

Baker, M.; L. Litov; J. Wachter; and J. Wurgler. "Can Mutual Fund Managers Pick Stocks? Evidence from the Trades Prior to Earnings Announcements." Journal of Financial and Quantitative Analysis, 45 (2010), 1111-1131.

Barberis, N.; A. Shleifer; and R. Vishny. "A Model of Investor Sentiment." Journal of Financial Economics, 49 (1998), 307-343.

Bennett, J.; R. Sias; and L. Starks. "Greener Pastures and the Impact of Dynamic Institutional Preferences.” Review of Financial Studies, 16 (2003), 1203-1239.

Bushee, B., and C. Noe. "Corporate Disclosure Practices, Institutional Investors, and Stock Return Volatility.” Journal of Accounting Research, 38 (2000), 171-202.

Cai, F., and L. Zheng. "Institutional Trading and Stock Returns." Finance Research Letters, 1 (2004), $178-189$.

Carpenter, J. "The Optimal Dynamic Investment Policy for a Fund Manager Compensated with an Incentive Fee.” Journal of Finance, 55 (2000), 2311-2331.

Chan, L. K. C.; H. Chen; and J. Lakonishok. "On Mutual Fund Investment Styles.” Review of Financial Studies, 15 (2002), 1407-1437.

Cohen, R.; P. Gompers; and T. Vuolteenaho. "Who Underreacts to Cash-Flow News? Evidence from Trading between Individuals and Institutions." Journal of Financial Economics, 66 (2002), 409-462.

Cohen, R. B.; C. K. Polk; and B. Silli. "Best Ideas.” Working Paper, Harvard University (2010).

Cornell, B., and R. Roll. "A Delegated-Agent Asset-Pricing Model." Financial Analysts Journal, 61 (2005), 57-69.

Coval, J. D., and E. Stafford. "Asset Fire Sales (and Purchases) in Equity Markets." Journal of Financial Economics, 86 (2007), 479-512.

Cremers, M., and A. Petajisto. "How Active Is Your Fund Manager? A New Measure That Predicts Performance.” Review of Financial Studies, 22 (2009), 3329-3365.

Cuoco, D., and R. Kaniel. "Equilibrium Prices in the Presence of Delegated Portfolio Management." Journal of Financial Economics, 101 (2011), 264-296.

Daniel, K., and T. Moskowitz. "Momentum Crashes." Swiss Finance Institute Research Paper No. 13-61; Columbia Business School Research Paper No. 14-6; Fama-Miller Working Paper (2013).

Del Guercio, D. "The Distorting Effect of the Prudent-Man Laws on Institutional Equity Investments." Journal of Financial Economics, 40 (1996), 31-62.

DeVault, L.; R. Sias; and L. Starks. "Who Are the Sentiment Traders? Evidence from the CrossSection of Stock Returns and Demand." Working Paper, University of Arizona and University of Texas (2014).

Edelen, R. M.; O. S. Ince; and G. B. Kadlec. "Institutional Investors and Stock Return Anomalies." Working Paper, University of California at Davis and Virginia Tech (2014).

Edmans, A.; I. Goldstein; and W. Jiang. "The Real Effects of Financial Markets: The Impact of Prices on Takeovers.” Journal of Finance, 67 (2012), 933-971.

Falkenstein, E. "Preferences for Stock Characteristics as Revealed by Mutual Fund Portfolio Holdings." Journal of Finance, 51 (1996), 111-136.

Fama, E., and K. French. "The Cross-Section of Expected Stock Returns." Journal of Finance, 47 (1992), 427-465.

Fama, E., and J. MacBeth. "Risk, Return and Equilibrium: Empirical Tests." Journal of Political Economy, 81 (1973), 607-636.

Goldman, E., and S. Slezak. "Delegated Portfolio Management and Rational Prolonged Mispricing." Journal of Finance, 58 (2003), 283-311.

Gompers, P., and A. Metrick. "Institutional Investors and Equity Prices." Quarterly Journal of Economics, 116 (2001), 229-260.

Hirshleifer, D.; J. Myers; L. Myers; and S. H. Teoh. "Do Individual Investors Cause Post-Earnings Announcement Drift? Direct Evidence from Personal Trades." Accounting Review, 83 (2008), 1521-1550.

Hong, H., and J. C. Stein. "A Unified Theory of Underreaction, Momentum Trading and Overreaction in Asset Markets.” Journal of Finance, 54 (1999), 2143-2184.

Jegadeesh, N., and S. Titman. "Returns to Buying Winners and Selling Losers: Implications for Stock Market Efficiency." Journal of Finance, 48 (1993), 65-91.

Jiang, H.; M. Verbeek; and Y. Wang. "Information Content When Mutual Funds Deviate from Benchmarks.” Management Science, 60 (2014), 2038-2053.

Khan, M.; L. Kogan; and G. Serafeim. "Mutual Fund Trading Pressure: Firm-Level Stock Price Impact and Timing of SEOs.” Journal of Finance, 67 (2012), 1371-1395. 
Lakonishok, J.; A. Shleifer; and R. W. Vishny. "The Impact of Institutional Trading on Stock Prices." Journal of Financial Economics, 32 (1992), 23-44.

Lakonishok, J.; A. Shleifer; and R. W. Vishny. "What Do Money Managers Do?" Working Paper, Harvard University (1997).

Lewellen, J. "Institutional Investors and the Limits of Arbitrage." Journal of Financial Economics, 102 (2011), 62-80.

Maug, E., and N. Naik. "Herding and Delegated Portfolio Management: The Impact of Relative Performance Evaluation on Asset Allocation." Quarterly Journal of Finance, 1 (2011), 265-292.

O'Barr, W. M., and J. M. Conley. Fortune and Folly: The Wealth and Power of Institutional Investing. Homewood, IL: Business One Irwin (1992).

Roll, R. “A Mean/Variance Analysis of Tracking Error.” Journal of Portfolio Management, 18 (1992), $13-22$.

Wermers, R.; T. Yao; and J. Zhao. "Forecasting Stock Returns through an Efficient Aggregation of Mutual Fund Holdings." Review of Financial Studies, 25 (2012), 3490-3529. 